\title{
el túnel de hampton roads
}

J. O. BICKEL

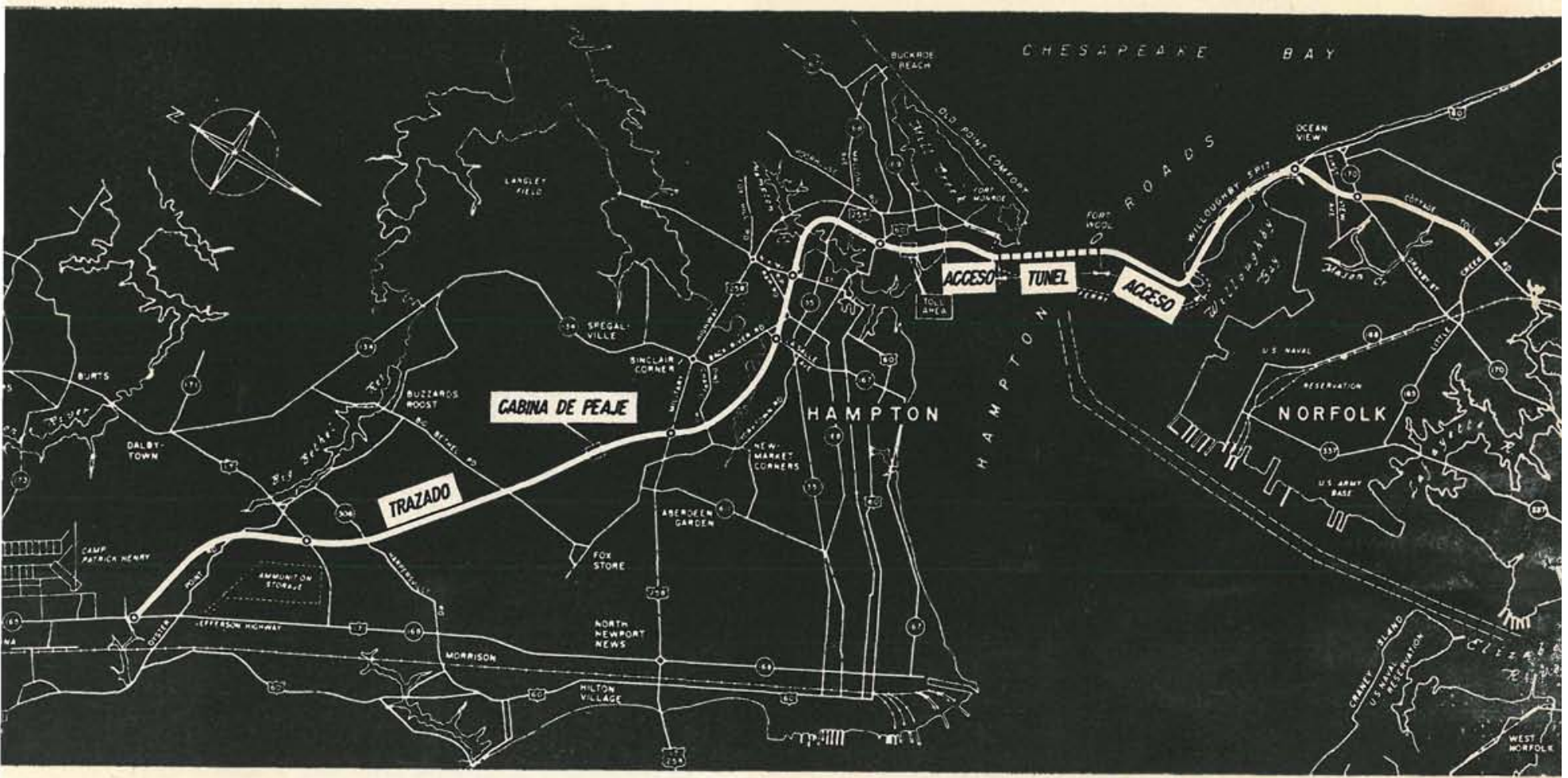

La Rada de Hampton (Hampton Roads) constituye el canal principal de entrada al puerto de Norfolk del Estado de Virginia (EE. UU.), a través de la bahía de Chesapeake. Como este puerto contiene una de las Bases principales de aprovisionamiento de la Marina de los Estados Unidos, así como otras importantes instalaciones navales, el mantenimiento de la navegación a través de esta vía es de extrema importancia. Al mismo tiempo, sin embargo, este brazo de mar constituye un serio obstáculo al transporte terrestre entre las diferentes ciudades y áreas industriales situadas en sus márgenes. Durante mucho tiempo los servicios de transbordadores han transportado automóviles y pasajeros de una orilla a la otra, en cantidades siempre crecientes, sufriendo retrasos y hasta paralización con mal tiempo o niebla. Esto ha motivado el proyecto y construcción de un paso permanente entre las dos márgenes.

\section{Elección del tipo de cruce}

En su punto más estrecho, la Rada de Hampton tiene $5 \mathrm{~km}$ de ancho. De éstos, $1.000 \mathrm{~m}$ corresponden al canal principal, y el resto está constitúdo por bajíos con profundidades máximas de $8 \mathrm{~m}$. Entre las soluciones se han estudiado un puente y un túnel. El primero requería un tramo principal de, por lo menos, $1.000 \mathrm{~m}$ de luz y una altura libre sobre el agua de $60 \mathrm{~m}$. Un puente colgante de estas dimensiones hubiera resultado muy costoso $\mathrm{y}$, además, inaceptable para la Marina, porque en caso de rotura, sabotaje o ataque aéreo podría obstruir el canal durante un período crítico. La construcción de un túnel bajo el canal pareció ser la única solución práctica.

\section{Descripeión general de la obra}

En la figura adjunta se da una idea del proyecto completo, que, del cruce subterráneo comprende, aproximadamente, $30 \mathrm{~km}$ de accesos para varias carreteras principales. A fin de proporcionar un flujo ininterrumpido de tránsito, hacia el túnel, los accesos consisten en dos carreteras paralelas de dos bandas de circulación cada una y numerosos pasos superiores, que eliminan cruces a nivel. Las entradas se han restringido en los cruces con otras carreteras principales.

El canal de navegación tiene una anchura de $1.000 \mathrm{~m}$ aproximadamente, y una profundidad de 11 a $24 \mathrm{~m}$. Los portales del túnel están alejados de las márgenes naturales, dentro de la bahía y sobre islas artificiales.

Se decidió, después de múltiples consideraciones, la construcción de dos islas artificiales en las aguas relativamente poco profundas, en las proximidades del canal, y construir sobre ellas los portales del túnel, apoyar los accesos a cielo abierto e instalar la estación de ventilación. Estas islas se unen a las márgenes mediante puentes de hormigón de baja altura. 


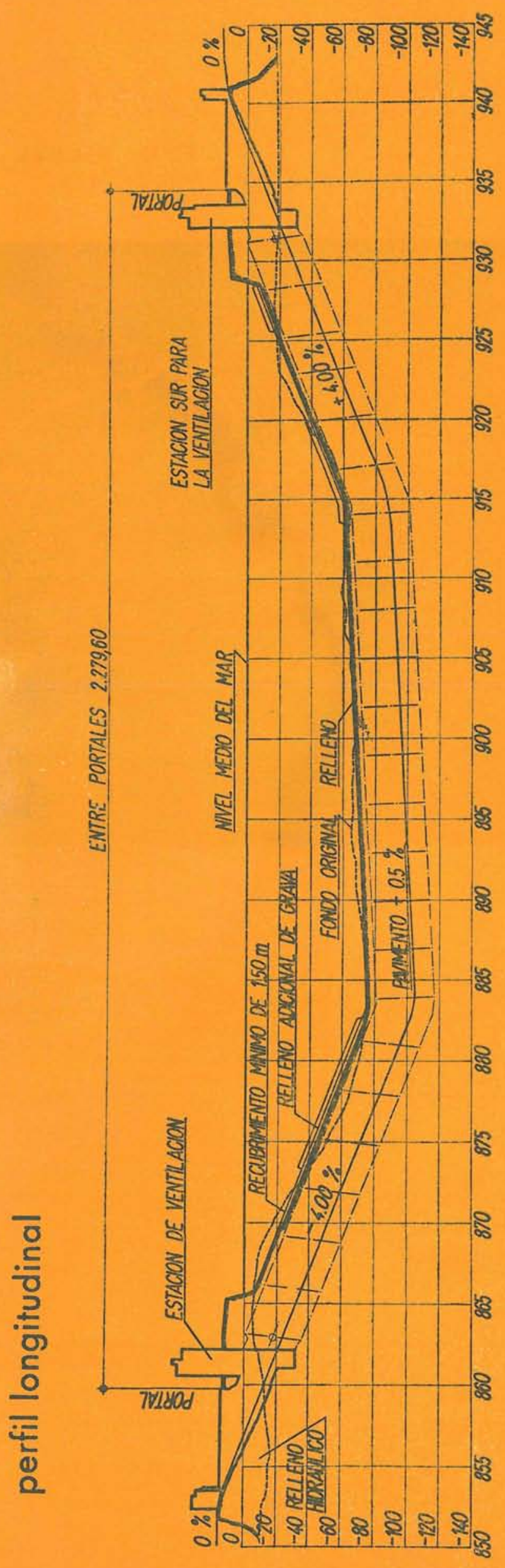

\section{El túnel}

El fondo del canal consiste, principalmente, de arena firme y algunas capas de limo en el lado sur. La arena aparece también bajo la isla norte y limo en el emplazamiento de la isla sur, que desciende hasta una profundidad de $25 \mathrm{~m}$. Estas condiciones eran favorables para la construcción de un túnel sumergido, excepto para los procedimientos especiales que se utilizaron en la isla sur.

Un túnel sumergido se construye por trozos de $90 \mathrm{~m}$ de longitud cada uno, prefabricados y sumergidos en una zanja dragada en el fondo del canal. Se necesitaron 23 trozos similares para cubrir una longitud algo mayor de $2.000 \mathrm{~m}$. Los $90 \mathrm{~m}$ adicionales de túnel en cada extremo se construyeron a cielo abierto y dentro de una ataguía, lo que dió una longitud total de $2.260 \mathrm{~m}$ entre portales. Desde los portales, los accesos abiertos se extienden por $180 \mathrm{~m}$ hasta el nivel del terreno con una pendiente del $4 \%$. La figura 4 ilustra secciones típicas a través del túnel prefabricado, la parte construída a cielo abierto y los accesos abiertos.

La estructura del túnel está constituída por una placa cilíndrica de $10 \mathrm{~m}$ de diámetro, de chapa metálica de $8 \mathrm{~mm}$ de espesor. La chapa se reforzó, longitudinalmente, con elementos metálicos de $127 \times 9,5 \mathrm{~mm}$ o secciones $\mathrm{T}$ de $100 \mathrm{~mm}$, de acuerdo con las cargas, que fueron soldados exteriormente al cilindro entre diafragmas transversales, exteriores, de refuerzo, espaciados a $4,50 \mathrm{~m}$. La chapa forma una membrana impermeable, y todas las juntas soldadas han sido ensayadas contra filtrajuntas soldadas han sido ensayadas contra filtraciones antes de colocar los trozos en obra. Al exterior del cilindro formado se fijó un encofrado mese prepararon en taller, y se transportaron sobre una plataforma flotante especial. Antes de cerrar los extremos con paredes provisionales de chapa de acero, reforzadas con perfiles I, se colocó la armadura para el revestimiento interior de hormigón y dura para el revestimiento interior de hormigon y se hormigonó la primera capa exterior. Los trozos próximo al lugar de ubicación del túnel. En este próximo al lugar de ubicacion del tunel. En este de $460 \mathrm{~mm}$ de espesor mínimo, y la losa de calzada, mientras los trozos flotaban a lo largo del muelle. Se emplearon encofrados metálicos, y todo el hormigón se bombeó desde una Central hormigonera. Terminado el hormigonado interior se cerraron los huecos de acceso de la clave del cilindro, se horhuecos de acceso de la clave del cilindro, se hormigonó la segunda capa exterior, y se colocó algún
balasto en los compartimientos laterales entre el balasto en los compartimientos laterales entre e operaciones dejaron los trozos flotando a $0.50 \mathrm{~m}$ de la superficie del agua y listos para su remolque al lugar de ubicación de la obra.

Una draga hidráulica se encargó de excavar uns zanja en el fondo del canal para colocar los trozos de túnel previamente preparados. A fin de sostener de túnel previamente preparados. A fin de sostener tenía profundidad suficiente para permitir la colocación de una capa de arena de $0,60 \mathrm{~m}$ de espeso mínimo.

Esta capa se niveló e igualó mediante una especie de draga de arrastre suspendida de una grúapuente soportada de un pontón compuesto de dos puente soportada de un ponton compuesto de dos barcazas metálicas paralelas. Las vias de la grua eran ajustables, de tal modo que pudieran ser exactamente paralelas a la pendiente final de la calzada en cada trozo de túnel. Las operaciones submarinas fueron controladas por medio de buzos, que regulaban el relleno de arena donde era necesario.

El trozo se descendió convenientemente amarrado en cada extremo a los aparejos montados sobre la estructura flotante utilizada en el enrasado, y añadiendo hormigón a los compartimientos exterioañadiendo hormigón a los compartimientos exterio-
res en cantidad suficiente para aumentar su peso res en cantidad suficiente para aumentar su peso
unas 100 toneladas más que el empuje de flotación. El trozo descendió lentamente, controlando su alineación mediante instrumentos en estación sobre torres especiales levantadas sobre la prolongación del eje del túnel. Estos aparatos visaban sobre mástiles de mira fijados temporalmente en cada extremo del trozo y que emergian sobre el agua. 
secciones transversales

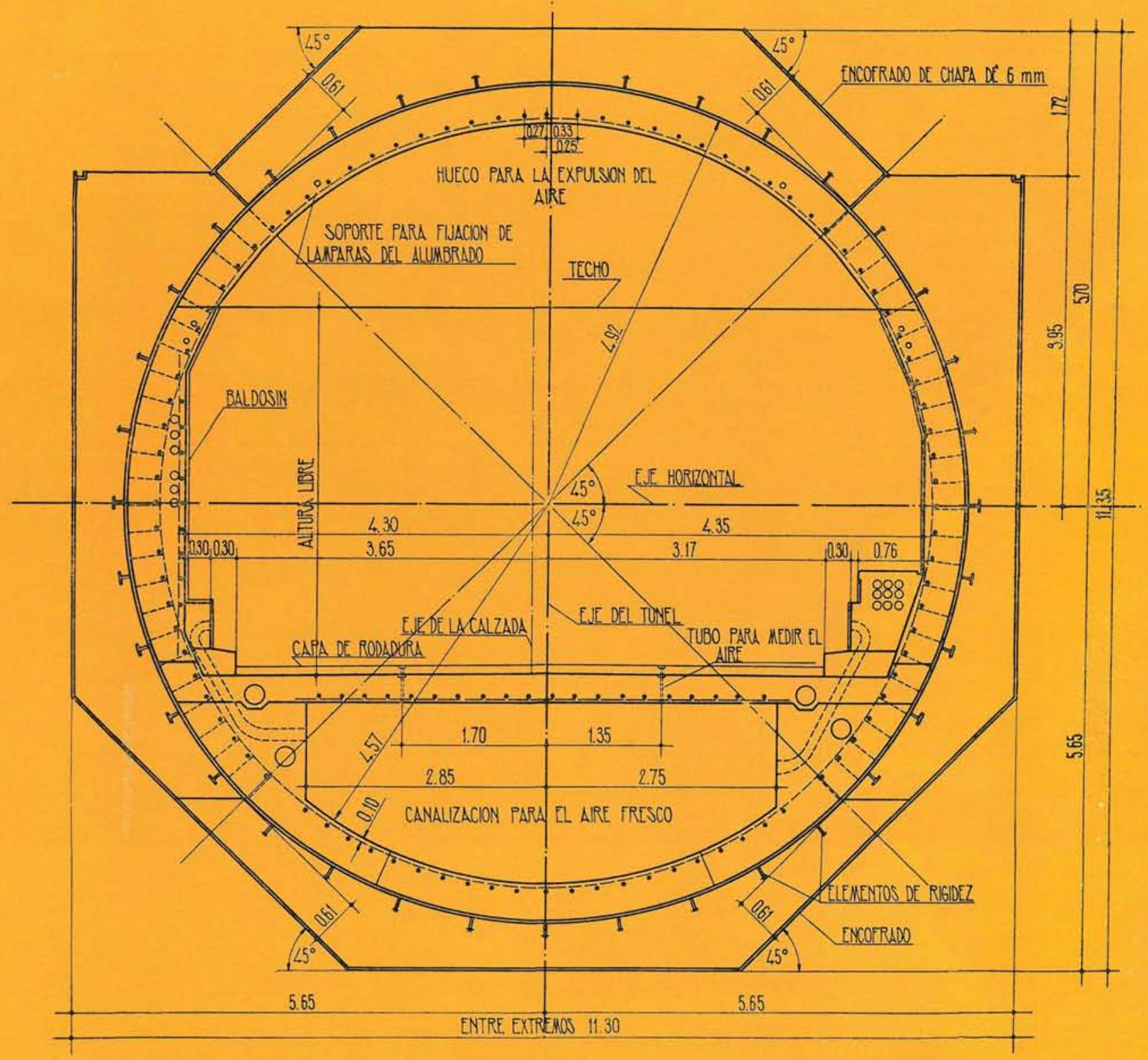

en túnel
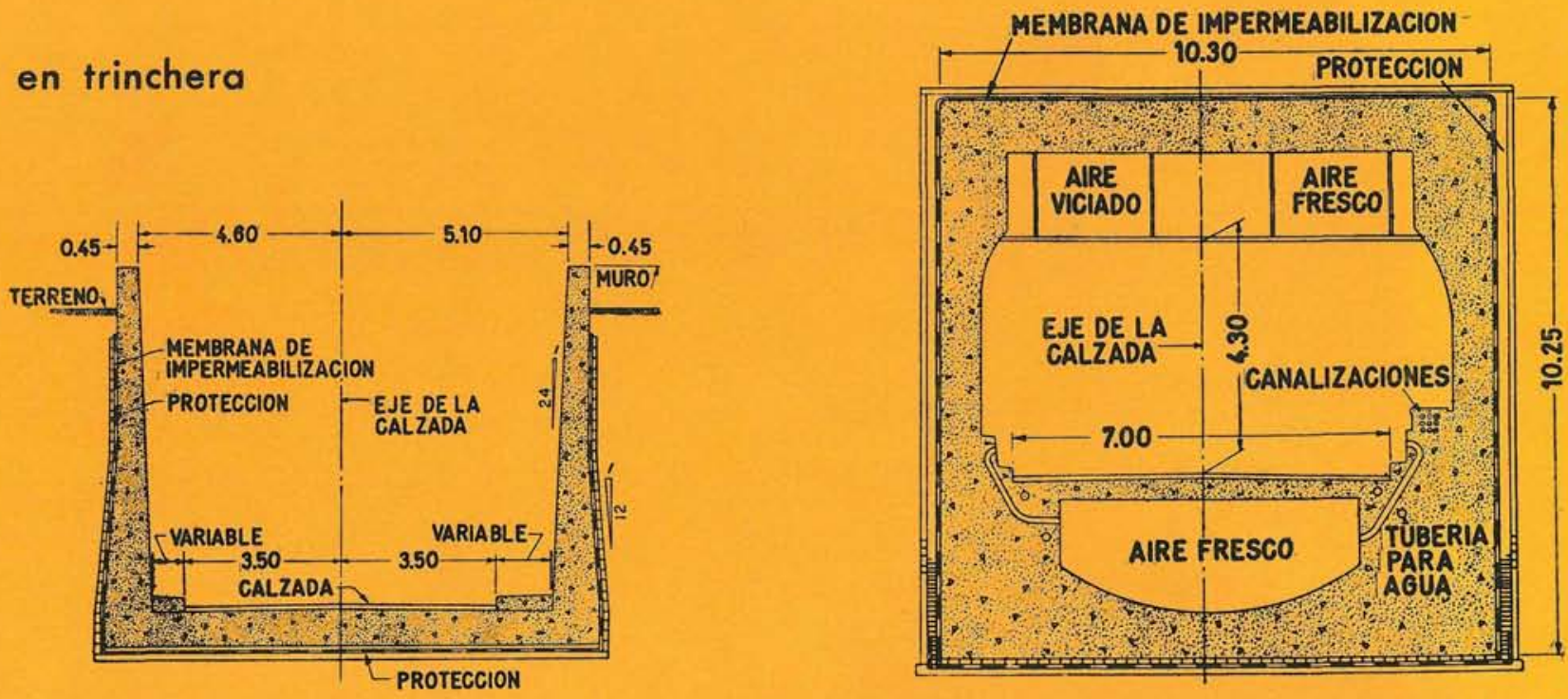


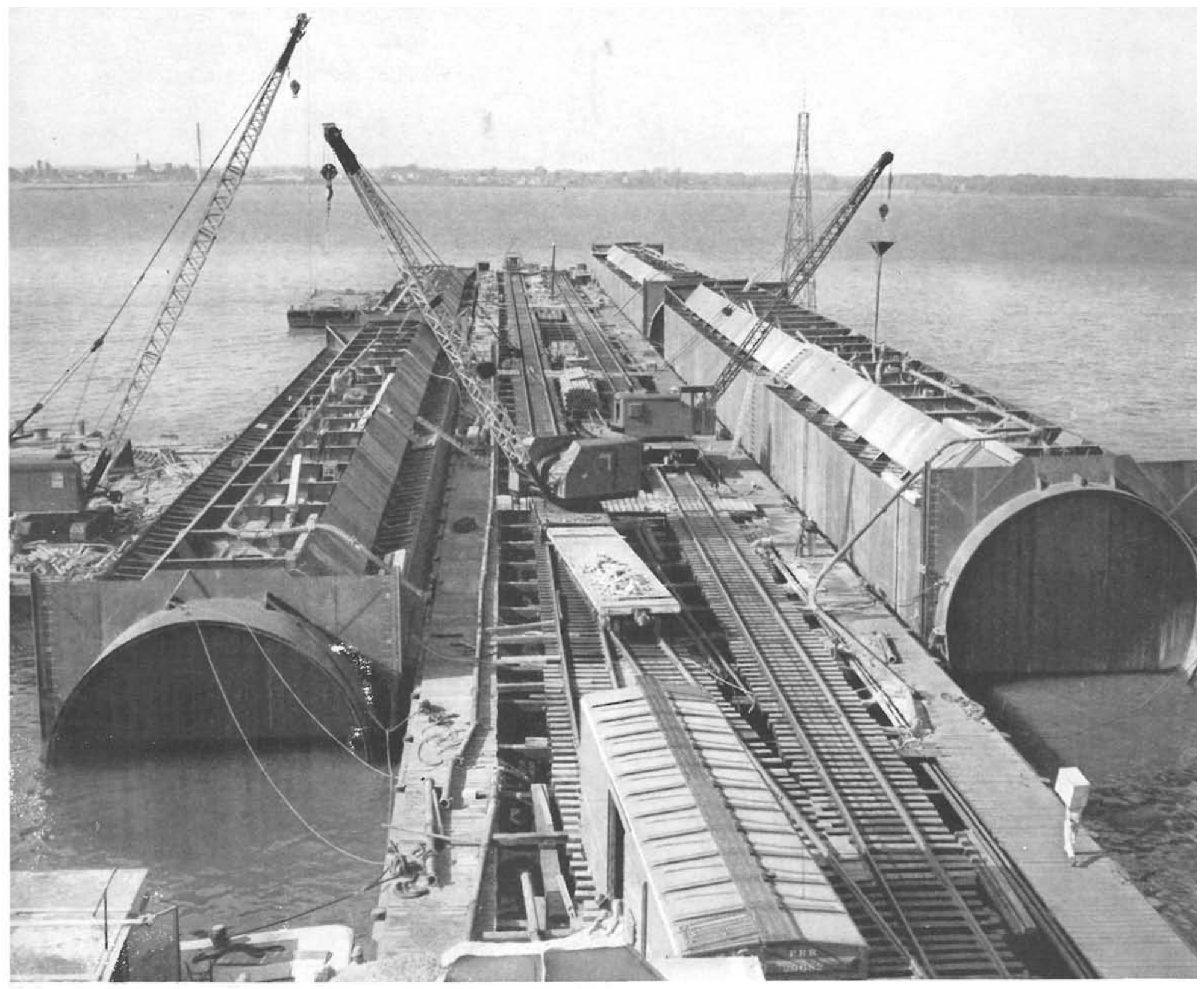

Trozos de túnel en el muelle de preparación.

Las juntas entre trozos se formaron con collares metálicos del mismo diámetro que el cilindro de acero, y se soldaron a los tabiques de cierre sobresaliendo $1,20 \mathrm{~m}$ de los mismos. En un extremo del trozo se soldó una chapa de acero, de $900 \mathrm{~mm}$ de ancho, a la parte inferior del trozo, y en el otro extremo se soldó otra chapa similar, pero fijada a la parte superior del trozo. Estas chapas sobresalían del borde del collar la mitad de su anchura. La chapa inferior constituye el soporte del próximo trozo. Para permitir un ajuste fácil, el radio de curvatura de la chapa interior es $25 \mathrm{~mm}$ mayor que el de la chapa que se ha de apoyar. Ya colocado un trozo se le llevaba hasta hacer contacto con el anterior mediante aparejos especiales manejados por buzos, con objeto de reducir al mínimo la acumulación de errores. Para mantener los trozos en contacto se utilizaron pasadores especiales de $125 \mathrm{~mm}$ de diámetro. Los bordes verticales de los tabiques cuadrados de cierre en cada extremo del trozo están equipados con dispositivos, similares a los engarces entre tablescuadrados de cierre en cada extremo del trozo están equipados con dispositivos, similares a los engarces entre tables-
tacas, en los cuales se alojan las extremidades de las chapas curvas que cierran la unión entre trozos. El espacio tacas, en los cuales se alojan las extremidades de las chapas curvas que cierran la unión entre trozos. El espacio
creado entre las chapas de cierre se hormigona con una tolva. Este procedimiento permite después poder abrir la chapa que cierra la extremidad de cada trozo y establecer el paso entre ellos.

Terminada la junta al exterior se procede a soldar una chapa de impermeabilización desde el interior y, finalmente, se termina de revestir con hormigón.

Los trozos descansan sobre arena, rellenando después la zanja y trozos con relleno ordinario a una altura no menor de $1,50 \mathrm{~m}$ por encima de la clave de los trozos.

La colocación de estos trozos empezó en la isla norte hasta el trozo núm. 7, colocando el núm. 23 en la isla sur. La colocación prosiguió después desde el extremo norte, permitiendo así trabajar en la construcción de las islas mientras se colocaba el resto de los trozos. Cada tres o cuatro semanas se colocaba un trozo. Se tomaron medidas especiales en la junta de cierre final entre los trozos números 21 y 22, a fin de poder corregir un error longitudinal acumulado, el cual, debido a la precísión en la prefabricación, colocación y replanteo, solamente fué de algunos centímetros. 


\section{Análisis del proyecto}

Desde el momento de la botadura del trozo hasta que llega a su posición final y ser cubierto por el relleno, estos elementos pasan por una serie de etapas con distintas condiciones de carga.

Las tensiones originadas durante la botadura, realizada lateralmente, han sido estudiadas. Al flotar, su peso se distribuye uniformemente, excepto en los mamparos extremos reforzados pesadamente, pues dan lugar a un momento negativo, produciendo tensiones longitudinales de flexión de, aproximadamente, $630 \mathrm{~kg} / \mathrm{cm}^{2}$ en la chapa de acero y en los nervios de refuerzo. A fin de reducir los momentos longitudinales en la estructura hueca del túnel, considerada en su totalidad, el hormigonado del interior, que se realiza en varias tongadas, se comienza cerca de los puntos que corresponden al cuarto de la longitud simétricamente en ambas direcciones. Por otra parte, la presión hidrostática exterior produce tensiones de flexión, tanto transversales como longitudinales en la estructura y momentos flectores en el armazón del diafragma, a medida que el calado de la estructura aumenta debido al peso del revestimiento de hormigón que se va agregando continuamente. Teniendo en cuenta las conca o cilindro en la inmersión, se supuso que ésta debía ser horizontal y que el cilindro y los diafragmas se fijaban en el borde superior de la quilla de hormigón, formando un ángulo aproximado de unos 45 grados por debajo de la horizontal.

Barcazas para la submersión de trozos de túnel.

Cierre del portal en previsión de posibles inundaciones.

Estación para la ventilación.
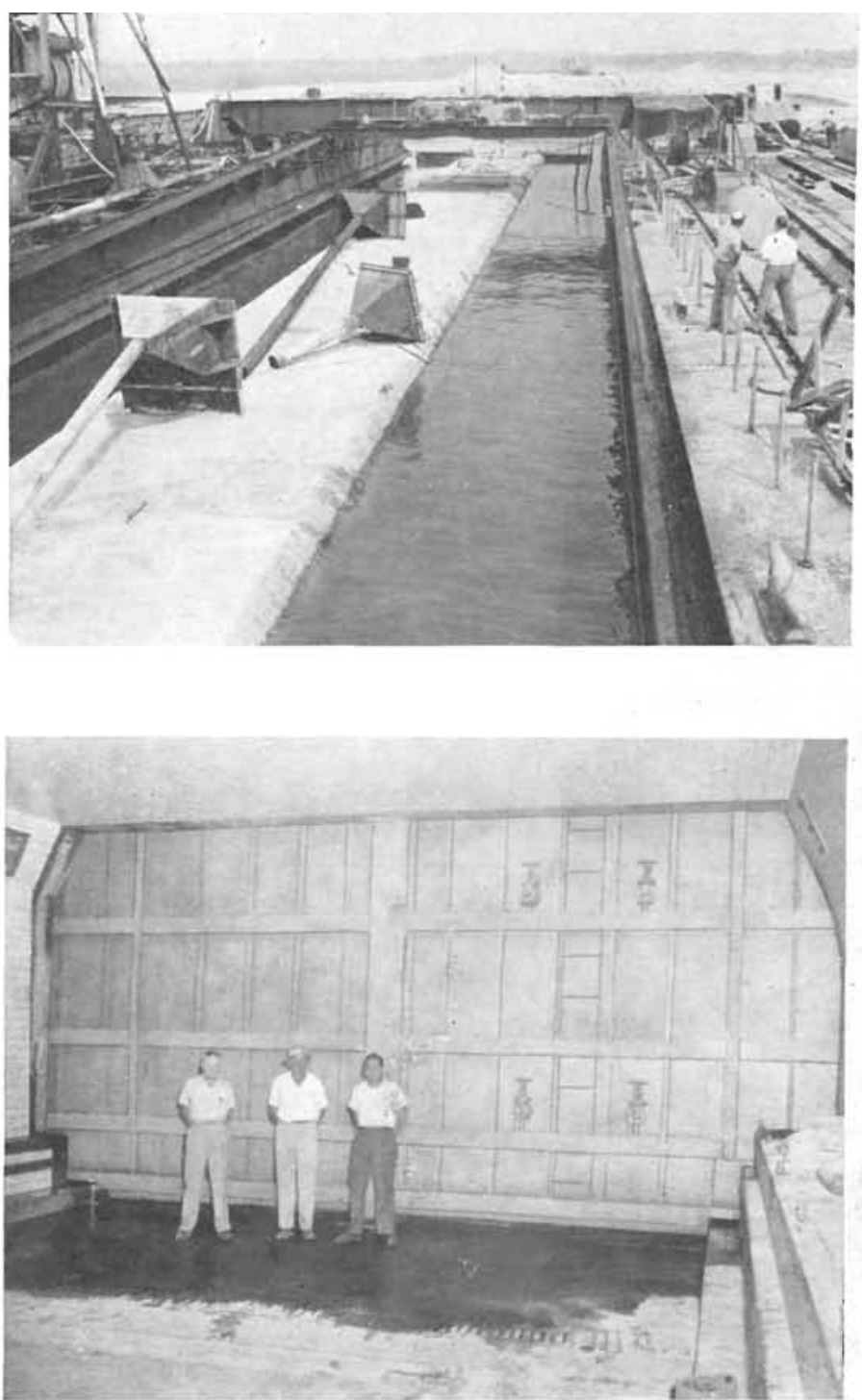

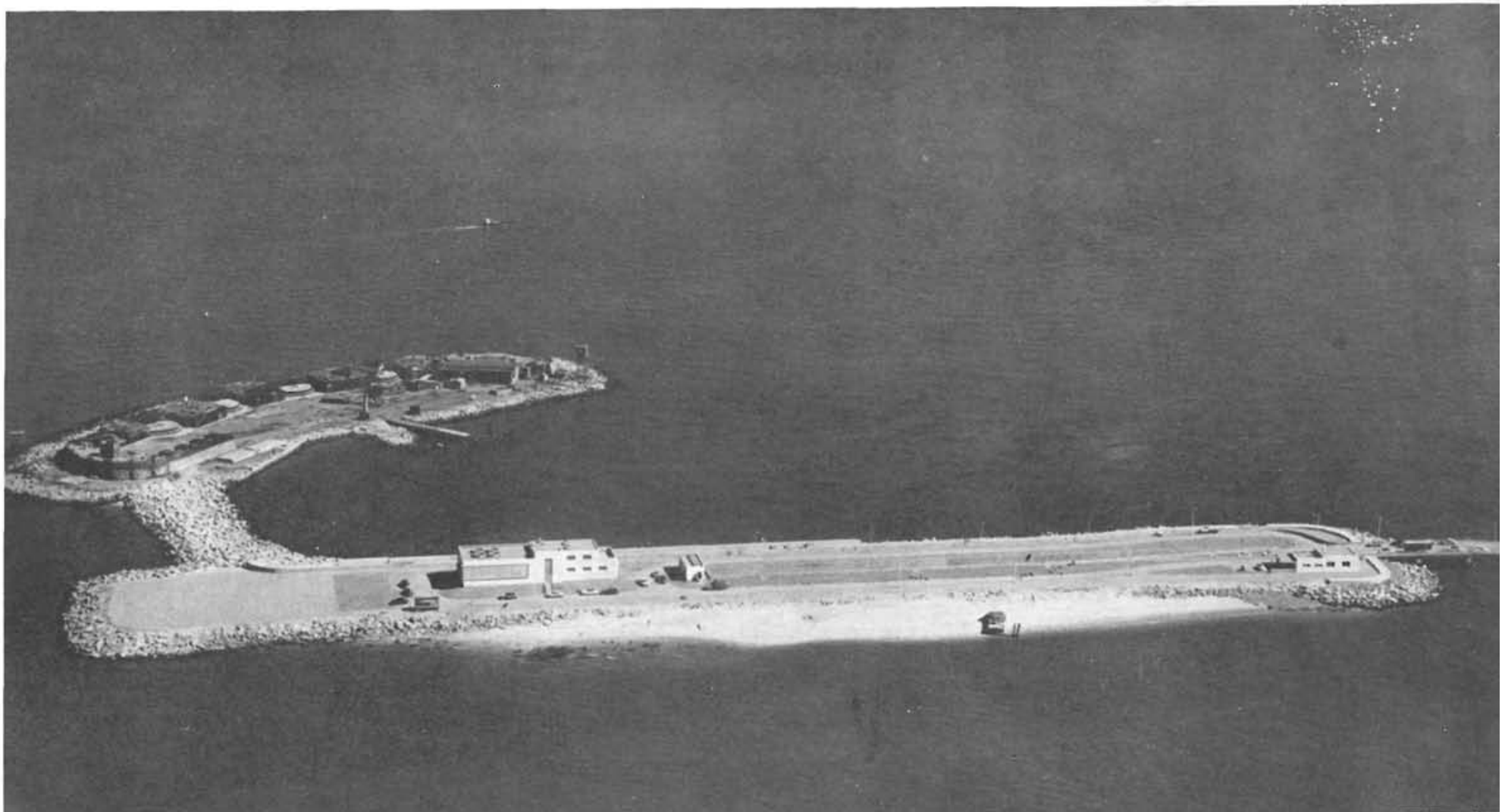




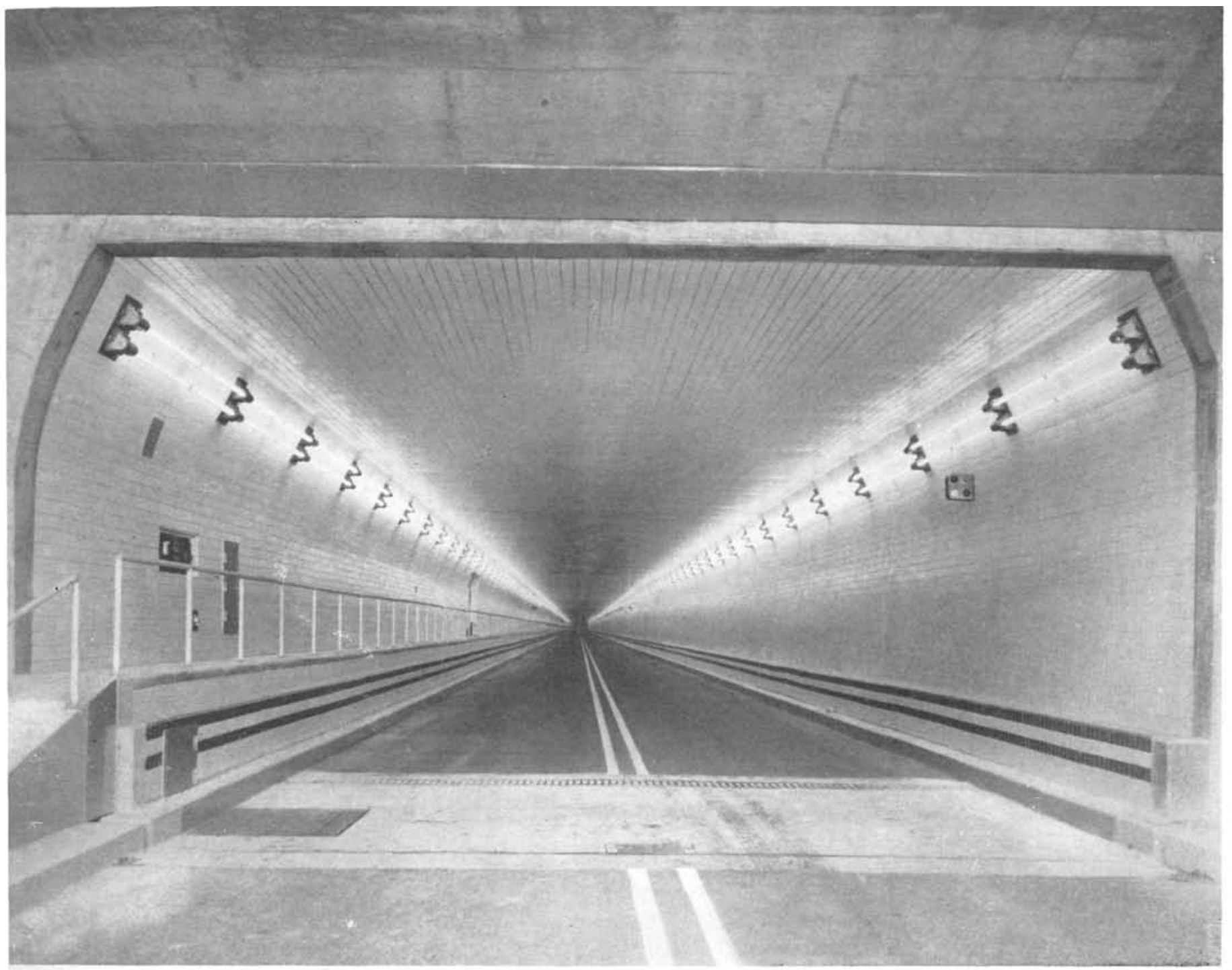

Interior del túnel.

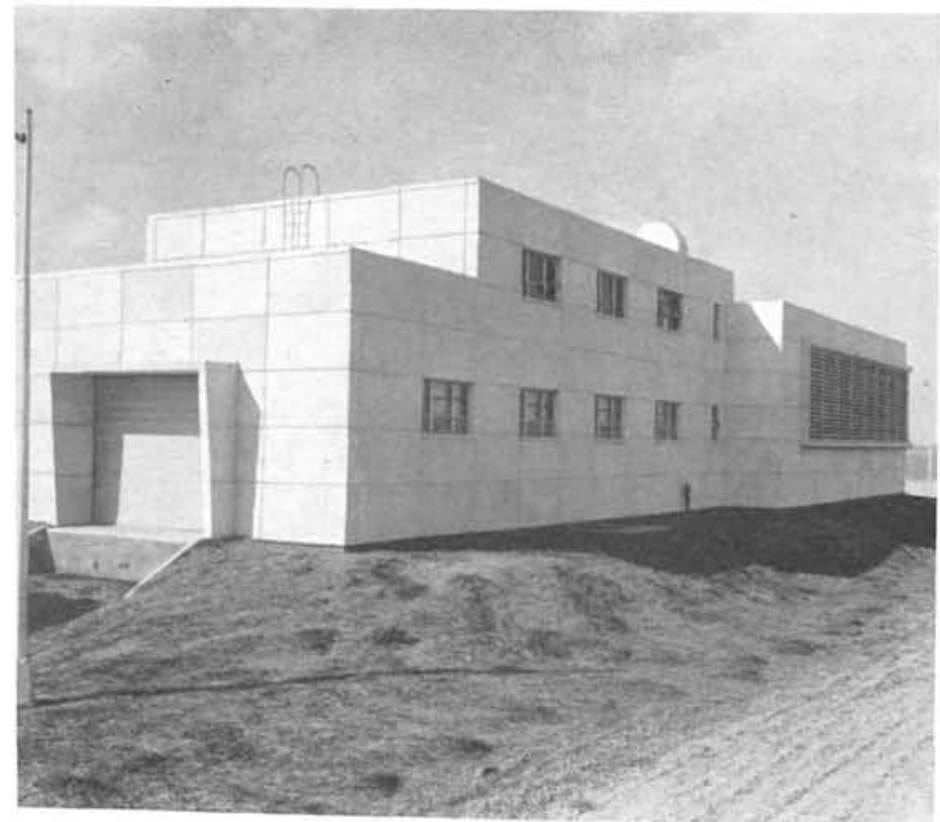

La acción opuesta de las capas de hormigón fresco del revestimiento se despreció. Estas hipótesis son algo conservadoras, puesto que la velocidad del hormigonado no produce, generalmente, incrementos $\tan$ grandes en la inmersión. Las tensiones en las diversas partes del cilindro se analizaron como se describe a continuación:

a) Flexión transversal en la estructura cilíndrica Se ha supuesto que el cilindro se comporta como una placa continua soportada por los elementos longitudinales de rigidez, sometidos a una presión exterior igual a la carga hidrostática. La tensión máxima de flexión en estas condiciones sería de $2.100 \mathrm{~kg} / \mathrm{cm}^{2}$, que se halla reducida debido a la rigidez que da la curvatura.

b) Flexión longitudinal.-La chapa del cilindro y los elementos de rigidez actuando conjuntamente transfieren la presión a los diafragmas que se hallan sometidos a una flexión que da $1.120 \mathrm{~kg} / \mathrm{cm}^{2}$ de tensión.

c) Tensiones en los diafragmas-Los cercos de los diafragmas se han supuesto empotrados en la parte superior de la quilla de hormigón. y sometidos a esfuerzos longitudinales y moy sometidos a esfuerzos longitudinales y mo-
mentos en la parte superior para ser aplicados el esfuerzo normal $\mathrm{H}_{c}$, corte $y_{c}$ y momento 
flector $M_{c}$, a fin de mantener el equilibrio. El momento flector en un punto cualquiera formando un ángulo $U$ con el plano horizontal es:

$$
\mathrm{M}_{u}=m_{u}-\mathrm{H}_{c} \mathrm{R}(1-\cos \mathrm{U}) / \mathrm{M}_{c} \text {, }
$$

donde: $m$ es el momento de las fuerzas exteriores; $R$, el radio del cilindro $\mathrm{H}_{c}$, el empuje, $\mathrm{y}_{c}$, el momento debido al empuje y esfuerzos normales.

Las tensiones máximas en el cerco del diafragma son de $900 \mathrm{~kg} / \mathrm{cm}^{2}$ a tracción y de $640 \mathrm{~kg} / \mathrm{cm}^{2}$ en compresión.

d) Cálculo de la estructura mixta del cilindro y hormigón.-La estructura completa se halla sujeta a dos condiciones de carga netamente diferenciadas: la presión hidroestática y la carga del relleno que cierra la zanja.

Si un cilindro uniforme tiene el peso mínimo necesario para su inmersión completa estará sujeto a tensiones normales, pero no a flexión. Aun cuando la sección del túnel no cumple exactamente esta condición, se analizó su comportamiento para justificar la hipótesis de la no existencia de momentos flectores durante su inmersión.

Las cargas actuantes sobre el túnel debido al relleno son:

Carga vertical sobre él, uniformemente repartida debida al relleno; presión horizontal, y la presión triangular debida al empuje de tierras. A estas cargas se unen la carga vertical debida a la tierra en los cuadrantes exteriores entre la clave del túnel y el eje horizontal, así como la reacción del túnel sobre cimientos.

Para calcular las tensiones correspondientes a estas cargas fué considerada la estructura como un cilindro de hormigón armado de $460 \mathrm{~mm}$ de espesor, reforzado con otro de acero y nervios, cuya parte inferior tiene función de quilla y la superior de hormigón en el exterior, que sirve de cubierta. El resto del hormigón exterior fué considerado como lastre.

Las tensiones unitarias máximas son: $1.400 \mathrm{~kg} / \mathrm{cm}^{2}$, a tracción para el acero estructural; $1.260 \mathrm{~kg} / \mathrm{cm}^{2}$ a tracción en armaduras para el hormigón, y $97 \mathrm{~kg} / \mathrm{cm}^{2}$ a presión en el hormigón. Se exigió una resistencia mínima a compresión, a los veintiocho días, de $210 \mathrm{~kg} / \mathrm{cm}^{2}$ para el hormigón armado.

\section{Condiciones del subsuelo}

Los sondeos realizados, encontraron dos materiales distintos. En la isla norte $\mathrm{y}$ al lado del canal están libres de limo, predominando un fondo de arena. Bajo el canal, de hasta $21 \mathrm{~m}$ de profundidad, se encontró una capa de limo de $9 \mathrm{~m}$ de espesor, cubierta parcialmente por' 3 a 9 metros de arena. Bajo la región de la isla sur, y en una faja de $450 \mathrm{~m}$ de ancho, a lo largo del límite sur del canal, el limo tiene una profundidad de 24 a $27 \mathrm{~m}$ por debajo del fondo.

El peso final del túnel es seis toneladas por metro, y el peso combinado con el relleno crea un sistema de fuerzas cuya resultante a lo largo de las aristas del túnel es nula o está dirigida hacia arriba, siempre que el relleno no sobresalga por encima del fondo natural de la bahía.

Por lo tanto, no se producirán asientos sobre los hasta $6 \mathrm{~m}$ de limo que aún quedaron en la trinchera después de su dragado.

En la isla sur surgió un problema especial, pues el tubo 22 estaba parcialmente apoyado en el limo y arena de la isla. Con objeto de impedir asientos, el relleno sobre este trozo es de esquistos expansionados, que no pesan más de $400 \mathrm{~kg}$ por $\mathrm{m}^{3}$ al sumergirlos en el agua del mar.

\section{Construcción de las islas artificiales}

La isla norte descansa sobre arena firme y, por tanto, no presentó problema alguno, a excepción de la compactación final del relleno para lograr la densidad suficiente para soportar las cargas sin asientos.

Por otra parte, el limo profundo en el lado sur planteó un problema de considerable magnitud. Los sondeos indicaron que el limo predominaba sobre una extensión que no podía evitarse por un desplazamiento del eje del túnel, un cual motivó que se estudiasen varias soluciones; entre ellas: el construir a cielo abierto el edificio de ventilación y los accesos sobre pilotes, sin relleno, formando isla, solución que requería proteger las estructuras contra daños producidos por cualquier navio que se desvie del canal.

Soportar dichas estructuras sobre pilotes hincados a través de una isla de arena formada sobre el limo, y cuya misión principal sería proteger las estructuras contra colisiones por navíos $\mathrm{y}$, finalmente, consolidar el limo.

La solución adoptada ha consistido en dragar el limo y reemplazarlo por un relleno de arena. Los ensayos sobre muestras inalteradas indicaron que se podían obtener taludes de $2: 1$ a profundidades por debajo de la cota $-15 \mathrm{~m}$, $\mathrm{y}$ de $2,5: 1$ en las capas superiores. La arena empleada para el relleno se pres- 
taba a una excavación, con dragado de succión, de bancos próximos al lugar del relleno.

Durante el relleno, el fondo de la tubería de descarga de arena se mantenfa a 1,50 $\mathrm{m}$ por debajo de la superficie del fondo, con objeto de lograr gran densidad en las capas de relleno.

Sin embargo, esto no resultó suficiente para lograr la densidad mínima relativa del $63 \%$, que se consideró necesaria para una profundidad de $6 \mathrm{~m}$ por debajo de cualquier estructura, ya que se quería evitar el empleo de pilotes.

Para comprobar el estado del relleno se verificaron varios sondeos. Se exigió que el relleno se compactara por vibroflotación. Para mejorar la compactación y grado de expulsión del agua el tiempo previsto para la compactación fué aumentando.

Bajo el edificio de ventilación, se compactó sólo la capa entre 13 y $19 \mathrm{~m}$ por debajo de la superficie, ya que el material por encima de mayor cota debía ser excavado. Para la compactación profunda se lastró a la máquina con una carga adicional de dos toneladas. Los resultados obtenidos por medio de esta compactación fueron muy satisfactorios.

La construcción de estructuras exteriores se realizó en seco, valiéndose de ataguías formadas con tablestacas $\mathrm{y}$ bombeo de agotamiento.

Estas estructuras se impermeabilizaron con un compuesto asfáltico mezclado con grava o cascotes de ladrillo y un agregado inerte, formando una capa de $0,50 \mathrm{~m}$ de espesor al exterior de las paredes.

Se han instalado dos ventiladores, subestaciones eléctricas, generadores de emergencia, cuadros de control y depósitos para materiales varios.

\section{Protección contra tormentas}

La isla norte está protegida contra tormentas severas por la saliente de old Point Comfort y por Fort Wool.

Las partes que no tienen protección natural se han reforzado por medio de diversos tipos de escollera que constituyen una protección artificial. En lo que respecta las corrientes submarinas se han tomado suficientes precauciones para evitar, dentro de los límites aceptables, toda clase de arrastres y lavados que pudieran poner en juego la seguridad de las islas artificiales.

En superficie la protección de los portales del túnel en las islas es a base de parapetos suficientemente altos para evitar irrumpan las olas e inunden al túnel.

Los portales, en previsión de posibles inundaciones, disponen de compuertas de cierre, $y$ las instalaciones auxiliares se han complementado con una estación de bombeo para el momento que este accidente pudiera ocurrir.

\section{Vontilación del túnel}

De acuerdo con los ensayos realizados, y basándose en la experiencia recogida en otros túneles existentes, el sistema de ventilación se proyectó para mantener un máximo de cuatro partes en 10.000 de monóxido de carbono en el aire bajo las condiciones más severas, circunstancias que sólo se presentan durante una gran congestión del túnel debida a tránsito muy lento o en caso de incendio. Para ello se requeririan 800 metros cúbicos de aire fresco por segundo, abastecidos por ventiladores instalados en ambos extremos del túnel. Este aire fresco es conducido a través de un conducto que se halla debajo de Este aire fresco es conducido a través de un conducto que se halla debajo de
la calzada, descargado el aire por toberas espaciadas a $4,50 \mathrm{~m}$ y situadas en el la calzada, descargado el aire por toberas espaciadas a 4,50 m y situadas en el de aberturas practicadas en el techo que conducen al conducto superior de salida del aire.

Cada central de ventilación contiene cuatro ventiladores de aprovisionamiento y cuatro de extracción, de $100 \mathrm{~m}^{3} / \mathrm{s}$ de capacidad máxima cada uno. El uso de ventiladores de corriente axial, en lugar de centrífugos como los instalados en túneles construídos anteriormente, permitió una reducción considerable en el volumen de las centrales. Paletas de paso variable y motores de dos velocidades incluídos en la campana de los ventiladores, permiten de dos velocidades incluídos en la campana de los ventiladores, permiten de los ventiladores como la inclinación de las paletas se controlan desde la sala de control de la central norte.

\section{Sistema eléctrico}

La energía eléctrica suministrada es de alta tensión. Los dieciséis ventiladores requieren un máximo de $4.800 \mathrm{~kW}$ y $550 \mathrm{~kW}$ para la iluminación y servicios.

El túnel se ha iluminado con luces fluorescentes continuas instaladas en la parte superior de los hastiales que dan una intensidad de 475 bujías/metro a la entrada y de 80 bujías/metro en el interior del túnel, facilitando así la acomodación gradual de la vista al conductor de vehículos. 

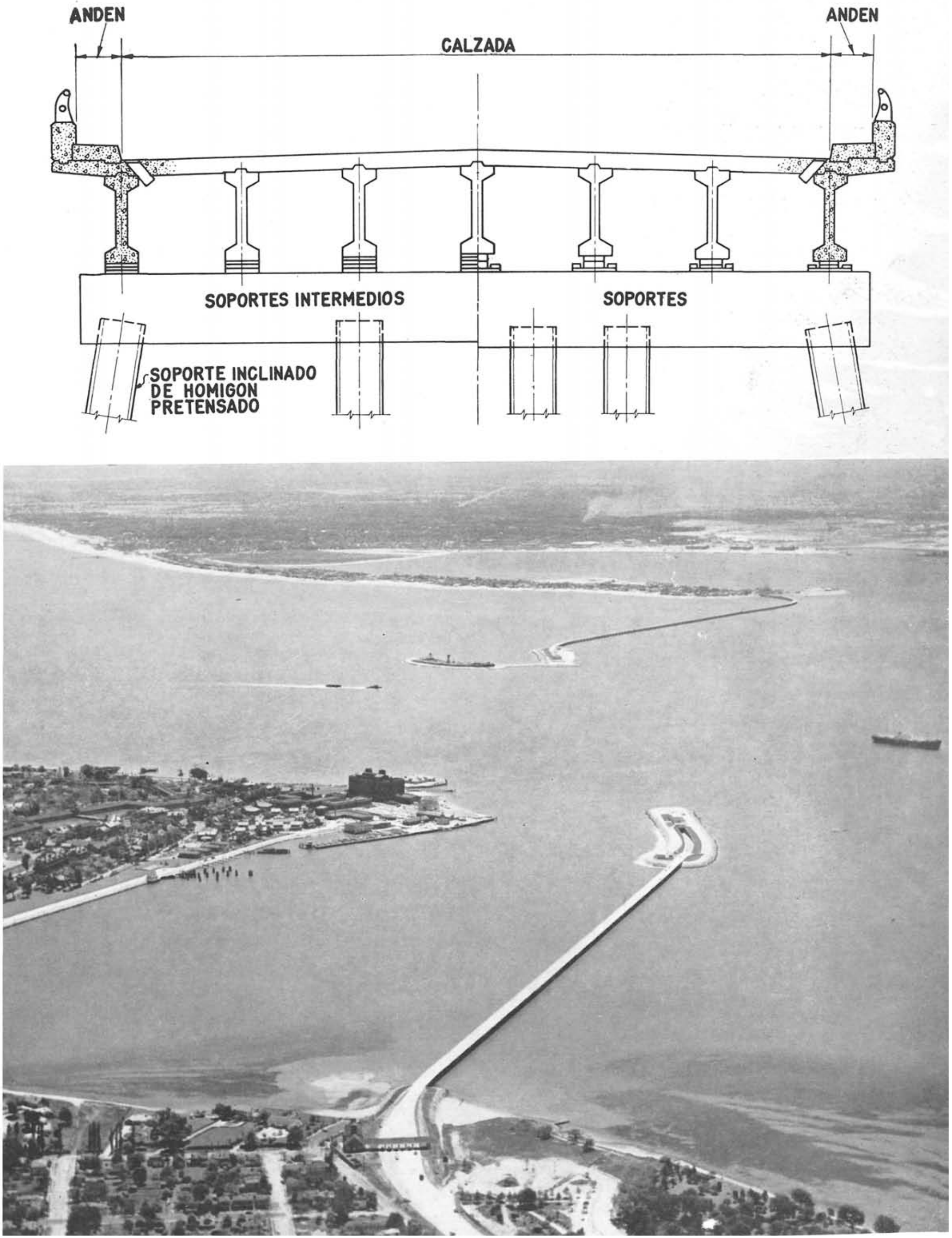


\section{Protección contra incendio y desagúes}

Para asegurar la circulación continua por el túnel se han previsto toda clase de desagües de aguas pluviales, bombeo, colectores y sumideros para facilitar la evacuación del agua.

También han sido objeto de consideración y previsión la instalación de bocas para mangueras contra incendios y cuantas medidas fueron necesarias para lograr la mayor seguridad contra todo riesgo.

\section{interior del túnel}

Las paredes del túnel están revestidas con azulejos cerámicos blancos. El techo consiste de paneles de aluminio terminados con porcelana esmaltada. Los paneles se han lastrado con hormigón para lograr mayor masa y disminuirlos.

\section{Accesos}

Las islas artificiales donde se hallan los portales del túnel se han unido con la costa portaies del tunel se han unido con la costa das tienen $9 \mathrm{~m}$ de ancho $\mathrm{y}$ dos bandas de das tienen $9 \mathrm{~m}$ de ancho y dos bandas de de hormigón pretensado, de 15 metros de longitud, soportadas sobre montantes formando palizada. En el acceso norte y en las partes menos profundas del acceso sur, los soportes tienen cinco montantes cilíndricos de hormigón pretensado, de $1,40 \mathrm{~m}$ de diámetro exterior y de $100 \mathrm{~mm}$ de espesor. Estos montantes se han prefabricado en trozos de $3 \mathrm{~m}$ de lonse han prefabricado en trozos de $3 \mathrm{~m}$ de lon-
gitud $\mathrm{y}$ se han pretensado longitudinalmente, gitud y se han pretensado longitudinalmente. de 18 a 25 metros.

El tiempo total de construcción para el cruce global fué de tres años.

La obra fué financiada con obligaciones sobre los ingresos, como parte del sistema de puentes de peaje bajo la jurisdicción del Department of Highways del Estado de Virginia.

La firma de estudios de ingeniería de New York, Parsons, Brinckerhoff, Hall \& Macdonald proyectó la obra y supervisó su construcción.

Merritt-Chapman \& Scott Corporation de New York y Tidewater Construction Company de Norfolk, Virginia, fueron los contratistas principales, los primeros para el túnel a tubo hundido, islas y puentes de accesos; los últimos para las secciones construídas a cielo abierto, los accesos abiertos, edificios de ventilación y sistemas eléctricos y mecánicos. El costo de construcción total para el cruce completo, de orilla a orilla, resultó de 29 millones de dólares, aproximadamente.

Esta obra se terminó en tres años, se financió siguiendo los principios de peaje y bajo los auspicios del Departamento de Carreteras de Virginia. La obra fué proyectada por la Casa Parsons, Brinckerhoff, Hall \& Macdonald, encargándose de nald, encargándose de su realización la Merritt-Chapman \& Scott Corporation. El presupuesto total de la obra se elevó a 29 millones
de dólares.

Sala de distribución y control.

Cuadro de mandos y control.

Ventiladores para la expulsión de aire viciado.
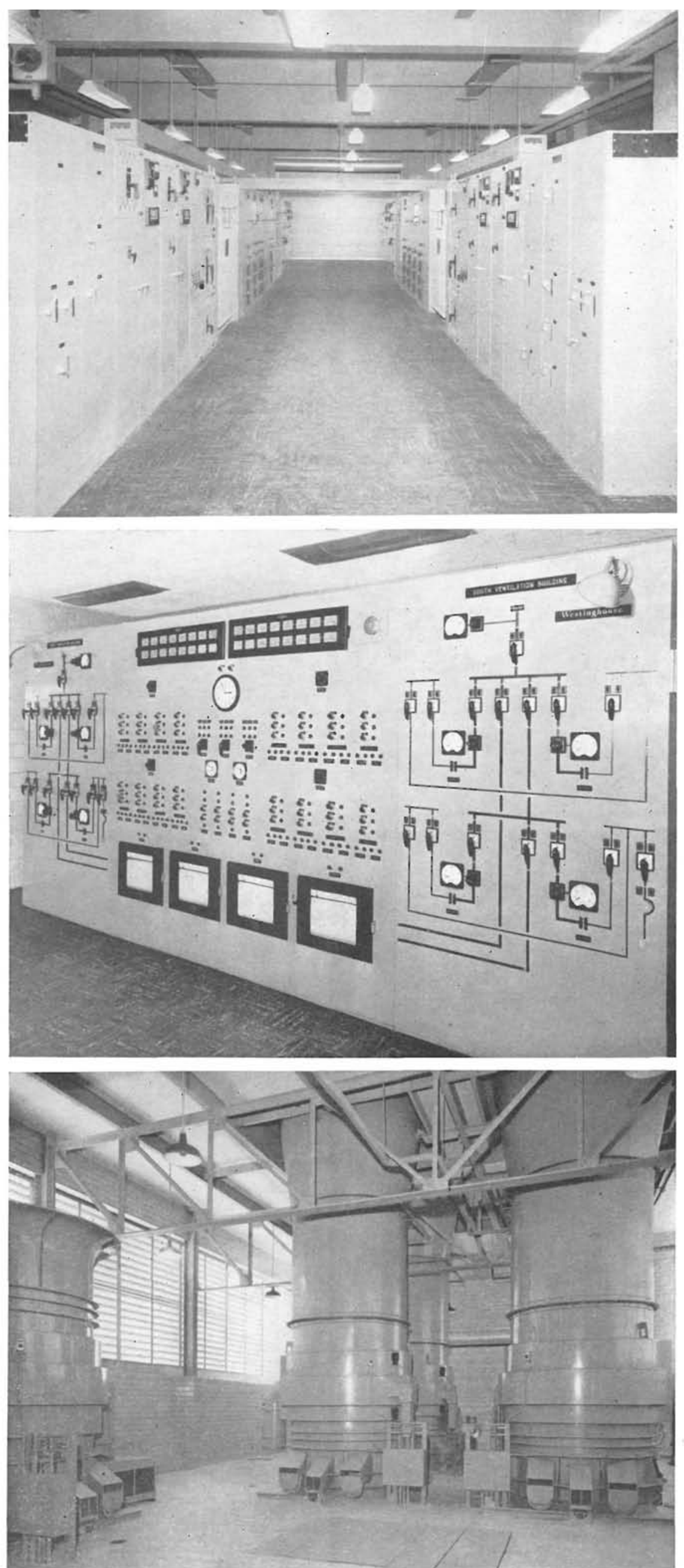